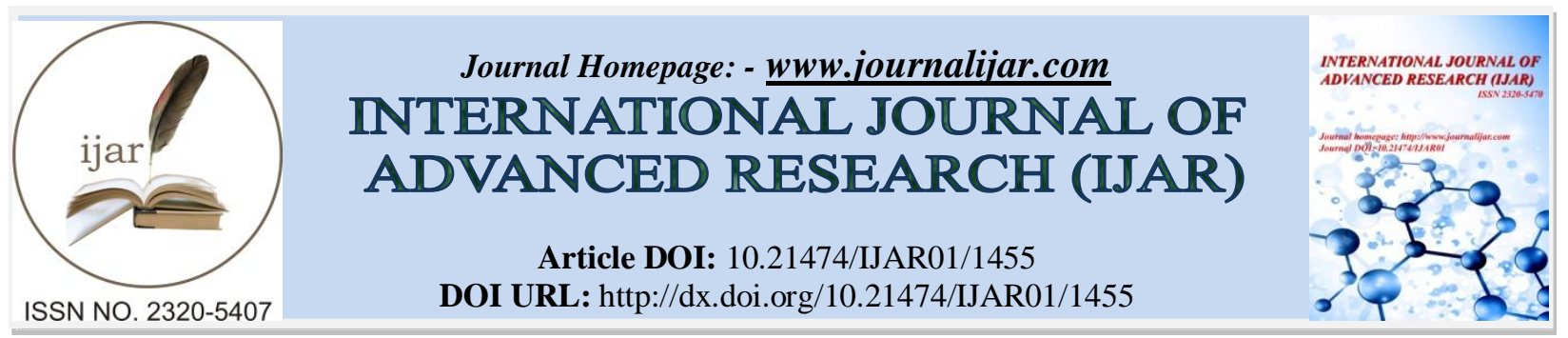

RESEARCH ARTICLE

\title{
COMBINED APPROACHES FOR THE AUTOMATIC DETECTION OF URBAN AREAS: APPLICATION TO THE STUDY OF URBAN SPRAWL OF CASABLANCA.
}

* MariamaZerhouni ${ }^{1}$, Abdelhamid Fadil ${ }^{2}$ and Mustapha Hakdaoui ${ }^{1}$.

1. Faculty of Sciences Ben Msik- Boulevard Cdt Driss Harti, BP 7955, Casablanca.

2. Hassania School of Public Works, 7 km, Route d'El Jadida, PO Box 8108Casablanca.

\section{Manuscript Info}

Manuscript History

Received: 19 July 2016

Final Accepted: 19 August 2016

Published: September 2016

Key words:-

Urban expansion,

spatial dynamic,

classification treatment,

\section{Abstract}

The spatial expansion of towns and cities is one of the main areas management urban planning. Indeed, this sprawl largely governs the form of the economic development of the city as well as the distribution mode and the population interaction with space.

The objective of this study is to evaluate the urban expansion of the economic capital of Morocco (Casablanca) during the last three decades quantifying the urban areas during this period and analyzing the form of this sprawl based on the observation techniques of the earth namely the images of the spatial detection.

So to visualize this spatial dynamics, Landsat TM sensor images, Landsat ETM + and OLI have been used for the monitoring of built areas.

The Classification treatments, the segmentation and the interpretation were used to map urban areas and thereby to deduce various forms of changes made in the study area.

The monitoring of this spatial dynamics is of great importance as it highlights the challenge of the urban planning and the management of the urban environment which are nowadays important issues for the country.

Copy Right, IJAR, 2016,. All rights reserved.

\section{Introduction:-}

The urbanization is a continuous change process and multidimensional that affects the whole world, its pace is hastening more and more in developing countries.

This is due to the fact that the city is the economic, the spatial, the demographic and the cultural, development engine that attracts many people to settle there. Thus, more than half of the world population currently lives in urban areas. In Africa, the urbanization rate will reach 56\% urban in 2050 (WUP, 2014). The continuing urbanization and the overall growth of the world population is expected, to add 2.5 billion people to the urban population in 2050 . This increase in urban population is accompanied by urban expansion that increasingly pushes the boundaries of the city to the periphery.

Certainly, the urban life is often associated to high levels of education, to better access to social services and to better opportunities for culture and policy to ensure the benefits of the urban growth equitably and sustainably 
(WUP, 2014) But when linking these latters to the uncontrolled and unplanned urban growth, we are witnessing the rapid urban sprawl, the environmental degradation and patterns of unsustainable production and consumption.

The urban sprawls studies are conducted to help monitor the spread of built up areas and thus quantify the degree of the urban sprawl. This allows to define the development trends and to avoid all complications that can be caused by this spreading as the inhabitants deteriorating living conditions, the endangering of the established ecosystems and in general, the biodiversity interruption (Yeh and $\mathbf{L i}, \mathbf{2 0 0 1}$ ).

In Morocco, the issues and complications of the urban expansion appear in a clearer way in large cities as Casablanca, which is the country's economic locomotive and its main social and urban population center . Thus, the present study is particularly interested in this area and its connections.

This conducted study is mainly based on medium resolution satellite images (15-100m) (Ruiz et al. 2013) and has as a fundamental objective mapping of urban areas, the analysis of the spatial spreading and the interpretation of this territorial dynamic to the views of different socio-demographic indicators of the study area.

\section{Material and Methods:-}

Study of the area:-

Casablanca is located in west-center of Morocco on the Chaouia plain at latitude $33^{\circ} 35^{\prime} 17^{\prime \prime}$ North and longitude $7^{\circ}$ $36^{\prime} 40^{\prime \prime}$ West (Figure 1). Spread over the Atlantic coast about $80 \mathrm{~km}$ south of the administrative capital of Morocco (Rabat), it is the main economic, financial and urban development center of our country.

It is characterized by a Mediterranean climate with a high ocean trend with relatively wet winters and moderately warm summers without precipitation. The annual average temperature is $18.8^{\circ} \mathrm{C}$ and annual total rainfall is about 426 mm (MRGC, 2010). According to the General Census of Population and Housing (RGPH) 2014 Casablanca has $3,359,818$ inhabitants, representing $10 \%$ of the total population of the Kingdom to an area of 386.14 km2(RGPH) ,2014).

The density of the population in this urban area is in the range of 8701.03 inhabitants / km2.

The population of the city has evolved at an annual average increase rate of $1.03 \%$ over the period 20042014.whereas at the national level, this indicator reached $1.25 \%$ between the rate of increase $2.2 \%$ of urban population and the rural population of around $-0.01 \%$ (RGPH, 2014).

From an administrative perspective, the city of Casablanca is integrated in the new Casablanca-Settat region according to the new territorial division of 2015. The Casablanca prefecture includes 16 districts in eight prefectures attached boroughs and the municipality of Mechouar. 


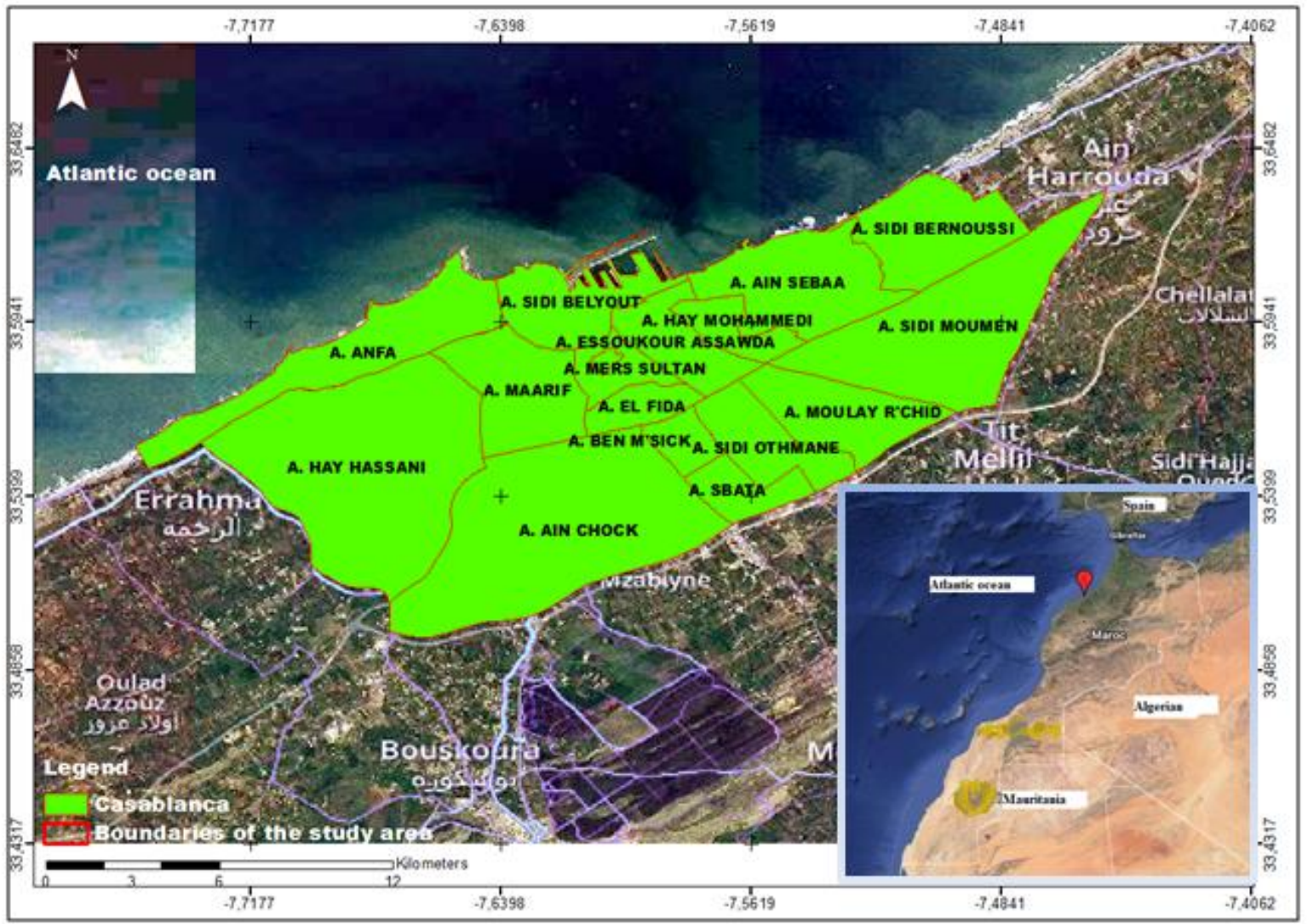

Figure 1:- Cutting and location of the city of Casablanca.

\section{Data and methodologies:-}

\section{Data:-}

We used three multidated Landsat images (TM and Landsat ETM + OLI) to the region of Casablanca. They are processed, classified and improved by remote sensing (Yeh and $\mathbf{L i}, \mathbf{2 0 0 1}$ ). Thus, information is extracted so as to map urban areas and to analyze later the territorial dynamics of the urban development.

Table 1 summarizes the characteristics of the data in question.

Table 1:- Characteristics of the used data.

\begin{tabular}{|c|c|c|c|c|}
\hline Data & Date & Data Supplier & Process & Output \\
\hline Landsat 7 TM (Thematic Mapper) & 26/9/1984 & $\begin{array}{l}\text { United States } \\
\text { Geological } \\
\text { Survey (U.S.G.S) }\end{array}$ & $\begin{array}{l}\text { Oriented classification pixel } \\
+\quad \begin{array}{l}\text { object-oriented } \\
\text { classification }\end{array}\end{array}$ & $\begin{array}{l}\text { Two maps of the } \\
1984 \text { built. }\end{array}$ \\
\hline 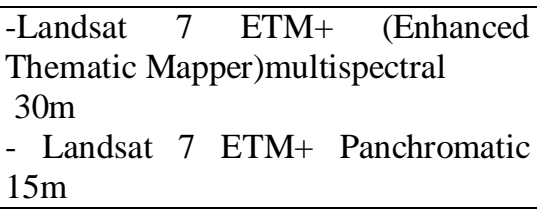 & $27 / 8 / 1999$ & U.S.G.S & $\begin{array}{l}\text { Object-oriented } \\
\text { classification }\end{array}$ & $\begin{array}{l}\text { Map of the } 1999 \\
\text { built }\end{array}$ \\
\hline $\begin{array}{l}\text { - Landsat } 8 \text { OLI (Operational Land } \\
\text { Imager)multispectral } \\
\text { - Landsat } 8 \text { OLI Panchromatic }\end{array}$ & $11 / 05 / 2015$ & U.S.G.S & $\begin{array}{l}\text { Object-oriented } \\
\text { classification }\end{array}$ & $\begin{array}{l}\text { Map of the } 2015 \\
\text { built }\end{array}$ \\
\hline The population census & $\begin{array}{l}1994,2004 \\
, 2014\end{array}$ & $\begin{array}{l}\text { High } \\
\text { Commission for } \\
\text { Planning(HCP) }\end{array}$ & & \\
\hline
\end{tabular}




\section{Methodologies:-}

To map and study the urban sprawl of Casablanca, three multidated Landsat images have been uploaded. They have been geometrically corrected to analyze successfully the multi-date developments and to have the exact position of each pixel (Ruiz et al., 2013).

Then, and to improve the detection of change of these images, two preprocessing operations were carried out namely the radiometric calibration and panchromatic refining:

* The first is to calibrate radiometric multispectral bands (DN converted their reflectance) is an important step to normalize the data.

* Whereas the second, it is to merge multispectral bands and the panchromatic band to have a high spectral and spatial resolution of the output image.

But the main treatment of the urban sprawl study from pre-processed satellite images is to classify the different pixels of the images into categories and thus extract those belonging to the class of buildings. This is commonly called the classification operation.

The Image classification is a process by which a label is assigned to objects (image pixels). There are several; we shall mention only the pixel-oriented and object-oriented.

In general, the classification involves four major steps:

* Selection of relevant attributes;

* Creating a vector of attributes per pixel;

* Choice of the label (if supervised);

* Learning classifier that can be activated in the case of object-oriented.

Several GIS software were used to implement this approach and subsequently to select the most appropriate classification in our case.

Table 2 gives a comparison between the two most used classification approaches namely oriented pixel classification and classification oriented to an object by focusing on the main characteristics of each method.

Table 2:- Comparison oriented pixel classification and that of the object-oriented. . (Lassieur2006),(Sparfel, Le Berre, 2008)et (L.Chekosgei, 2011).

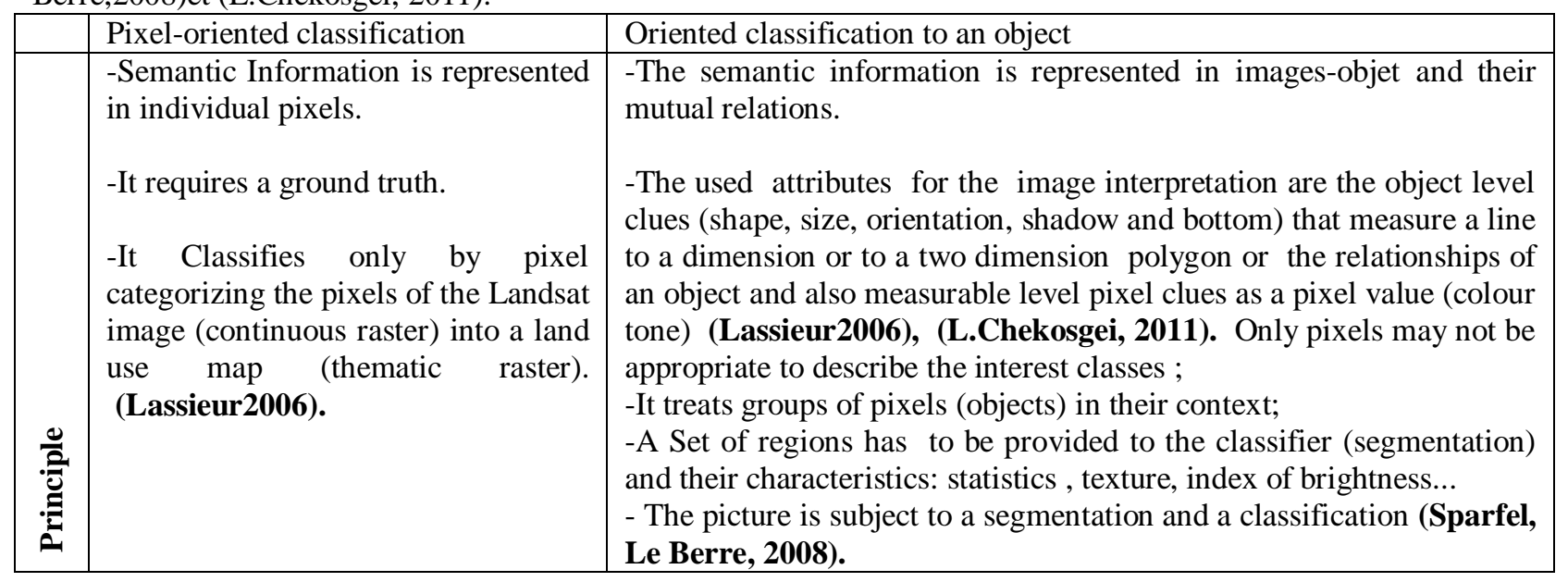




\begin{tabular}{|l|l|l|}
\hline The minimum distance of a & - A process is used for scanning drive plots. The machine learning \\
classification algorithm will classify & algorithm is adapted to this process, it manages continuous and \\
image pixels using the spectral & inconspicuous variables and learns from the training samples; \\
properties of learning classes. & - Trainings areas are then defined across the whole card, at this stage a \\
(Ruiz,Acosta,2013) & pixel classifier is formed from pixels representing the frame, subject to \\
- The image is interpreted by the & calculate benchmark metric pixels; algorithms marks quantify the \\
pixel level indices (color, texture, & human visual attributes by calculating the benchmark metric for the \\
sites) which are measured by the & index of the pixel level: the pixel candidates are subjected to pixel \\
pixel values (L.Chekosgei, 2011). & classifier to see how they look like at the training pixel. \\
- The definition of spectral signatures & On the other hand, the object level indexes are calculated on the \\
from the training plots and the & built polygons; (L.Chekosgei, 2011) \\
nomenclature of the selected classes & - The output is the probability of pixel layer in each value it is the \\
for the land use was mainly based on & probability that it is the object (built). \\
photo-interpretation. & -A filtering is performed on that pixel probability layer keeping only \\
-Concerning what is named control & the pixels with a probability greater than or equal to the threshold \\
plots, they are scanned and informed & value within the "built" class. The other pixels fit into the "unbuilt" \\
in the same way of the drive plots & class. \\
classification. They control and & A conversion of raster segmented in vector follows this step and \\
evaluate the resulting classification. & similar polygons (the same frame) emerge. \\
& -A Superposition and synchronization of this layer with a land card or \\
with "Google Earth" are necessary so that the performer picture can \\
lock its bitmap and thus validate this result compared to reality.
\end{tabular}

The oriented pixel classification is well known and is the approach traditionally used for mapping space from satellite images.

On the other side, the object-oriented classification is not widely used, particularly in the Moroccan context for its complexity and its implementation that is fairly difficult.

For this, one of the main objectives of this study was to compare the capabilities of these two classification methods to automatically detect the urbanized areas of Casablanca city and therefore to choose the most appropriate approach for its urban dynamics study.

To classify a satellite image pixel oriented way, algorithms developed and we' 11 mention only the minimum distance algorithm; this performs a calculation of spectral distance between the pixels to be classified and those trained (Y.Lanthier, 2009) .The minimum distance is the distance between the pixels and the average pixel trained for each class under consideration.

Object-oriented classification combines spectral and spatial information .So to interpret the image, indexes or attributes used by humans are divided into two categories: (L.Chekosgei, 2011)

* The pixel level indexes (colour, texture) measurable as a pixel value.

* The Level indexes of the object (shape, size, orientation) measure the relationship of an object (line, polygon). 
It is also based on automatic approaches.

The diagram of Figure 2 illustrates its operation in a mere way.

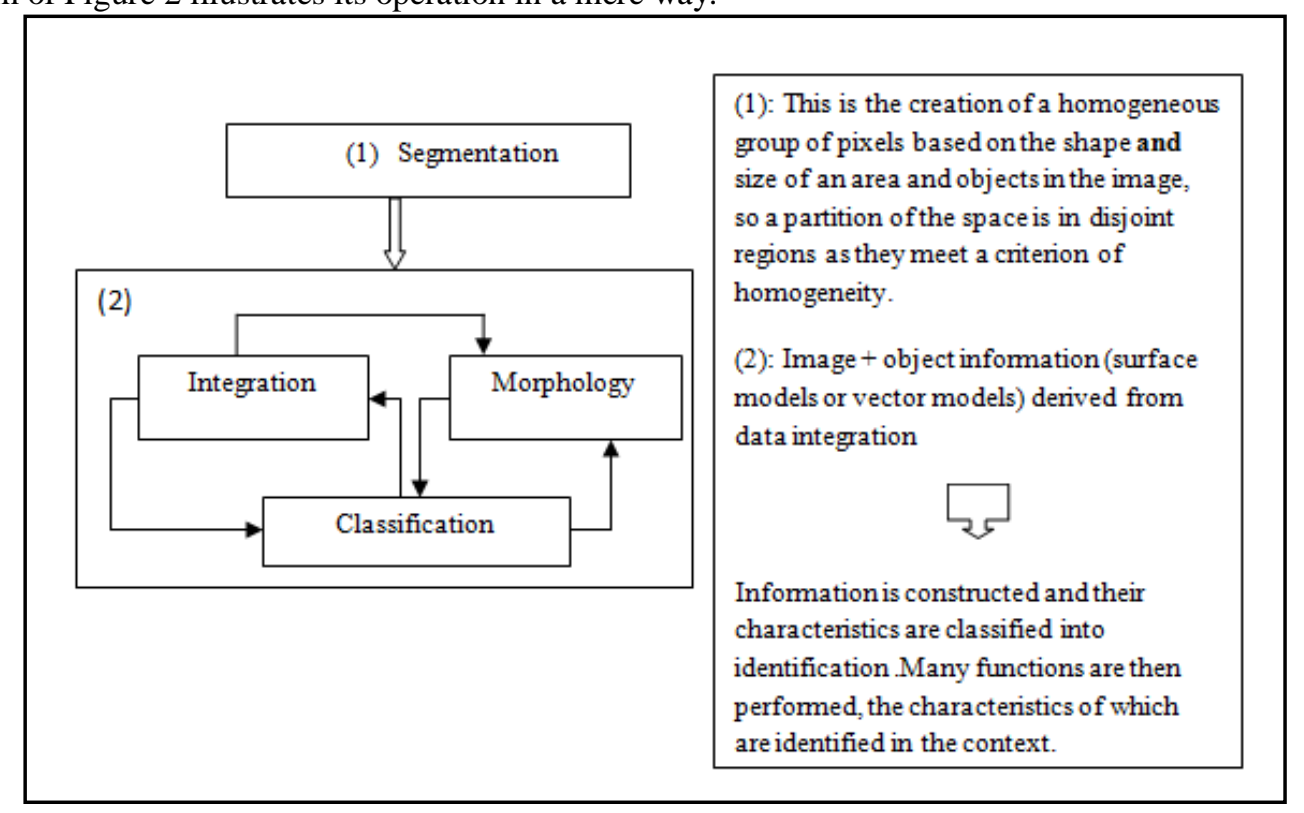

Figure 2:- Stages of object-oriented classification.

The context object is the specific component approach based on: we talk about spatial relationships between objects, that means that everything is connected and the closer the objects are, the more related they are likely; this idea is the same as the quotation mapping pioneer "Waldo Tobler" who said: "Everything is related to everything else, but near things are more related than distant things".

The segmentation is a spatially close pixels regrouping according to different similarities criteria. It works by searching the best neighbor according to a predefined criterion of color and shape. When the relationship is reciprocal homogeneity, the pair of points is matched. (O. Joinville2015) .This step merges the pixels into objects.

Then, spectral, spatial and contextual data on these objects are collected to guide the classification.

It should be noted that the first segmentation results and subsequently, the object quality are very influenced by the properties (spectral values) of the pre-processed image. (Taylor and F.Series, 2014).

The accuracy of the classification is determined by comparing the classes of the resulting image (raster result) for reference pixels representing the reality on the ground. This step is performed on the ground or with reference to more detailed satellite images like those of Google Earth.

Once the images are classified and urban areas are extracted from different satellite used images, the next step consists in the diachronic analysis for the study of territorial dynamics.

The diagram illustrated in Figure 3 shows the main steps of the image processing according to the approach of object-oriented classification for the study of urban dynamics of the city of Casablanca. 


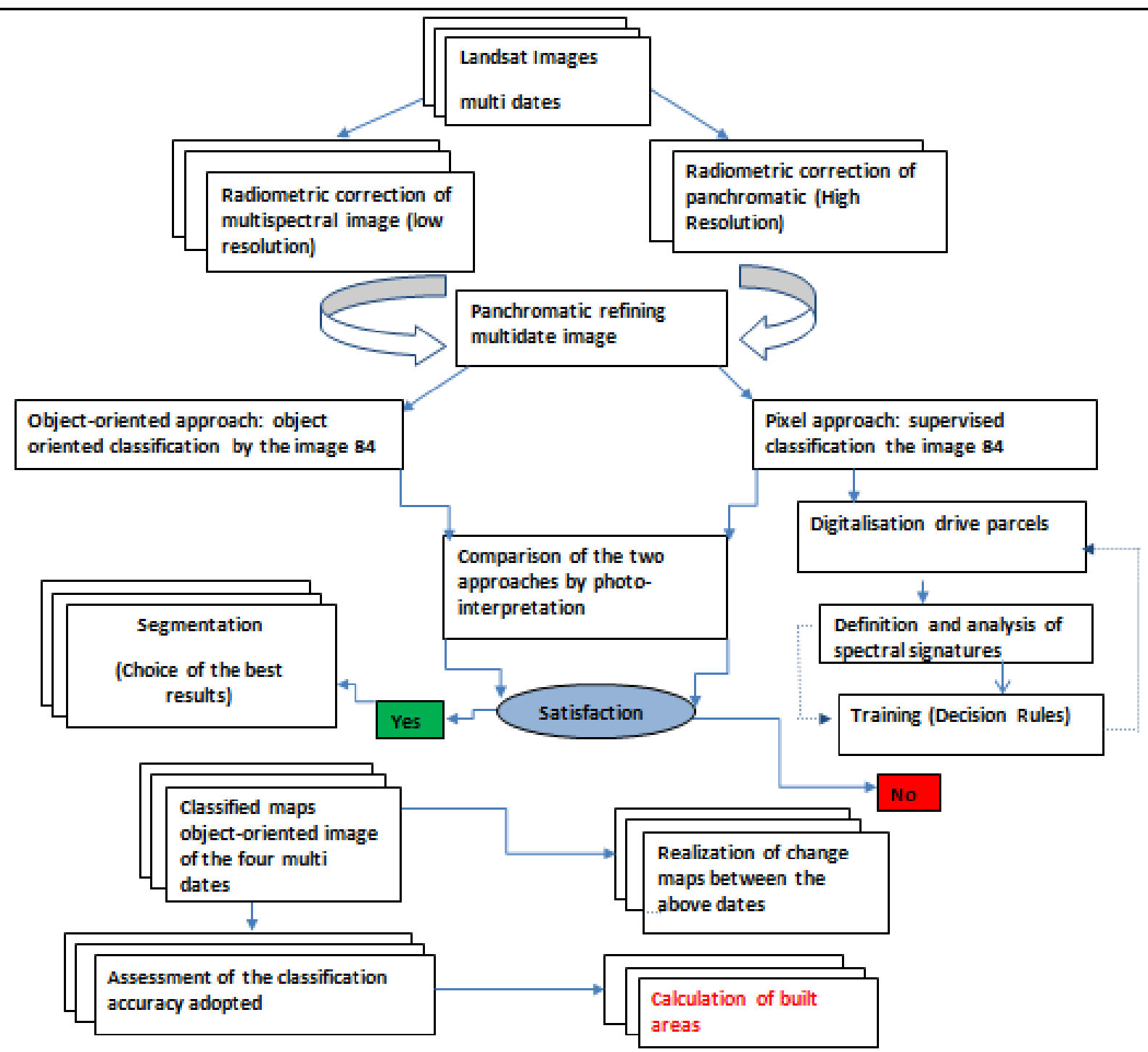

Figure 3:- Flowchart of the pretreatment and the production of the multi dates classified maps of Casablanca.

\section{Results and Discussion:-}

Résultats:-

Mapping of urban areas:-

Comparing the results of both approaches by photo interpretation and the classification of satellite image of the relevant date showed the effectiveness of the object-oriented approach that allowed better extract the urbanized areas.

Indeed, the comparison of the maps shown in Figure 4 and which are derived from the classification of Landsat images of 1984 by both approaches clearly show that in the level the of the pixel-oriented approach there is a distinctly considerable confusion between the two classes "sand" and "built" and between the classes "wave" and" built "and also between " roads", tracks " and" built " classes .see figure4 .This could be due to unclassified or misfiled pixels at spectrally heterogeneous land cover.

But, in the object-oriented approach, the separability of the classes was a major challenge. Also the uniformity and harmonization of the classified image (see figures4, 5 and 6 ) which are well demonstrated by the existence of pixelbased methods at the segmentation level. 


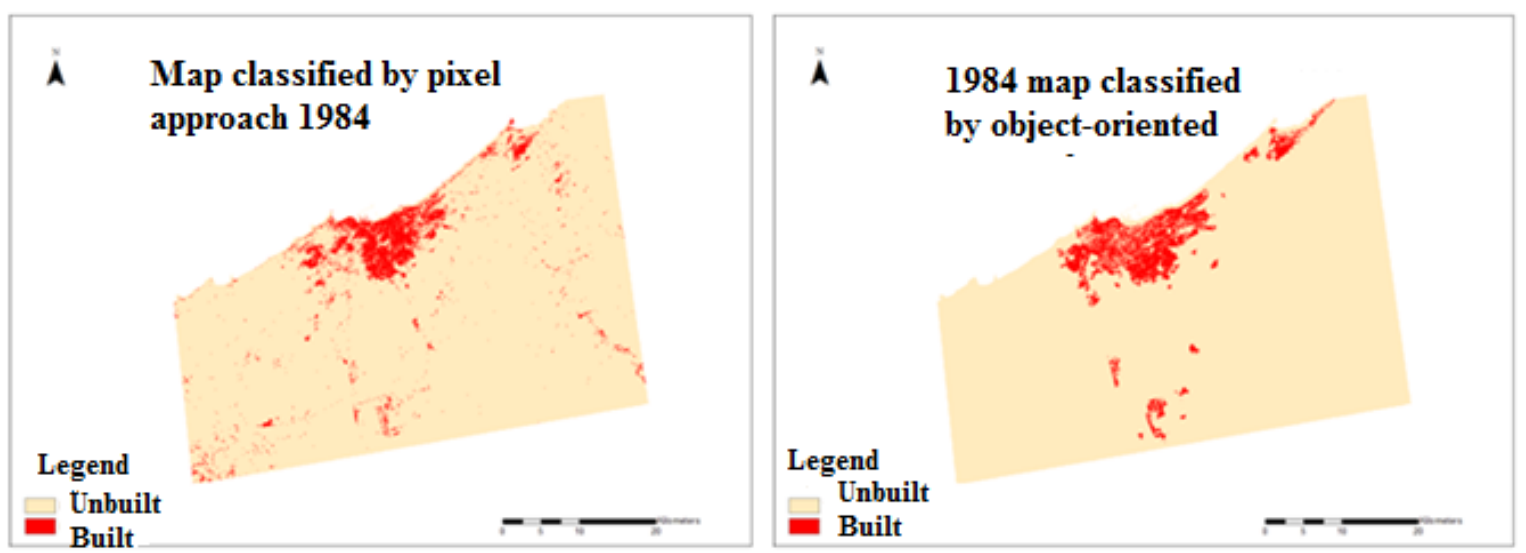

Figure 4:- Results of oriented pixel classification and object-oriented classification of Casablanca satellite image in 1984.

In addition, the digitized map built by photo-interpretation from the 1984 satellite image is clearly superimposed with the map of the object-oriented approach, unlike that of pixel-oriented approach, as shown in Figure 5.

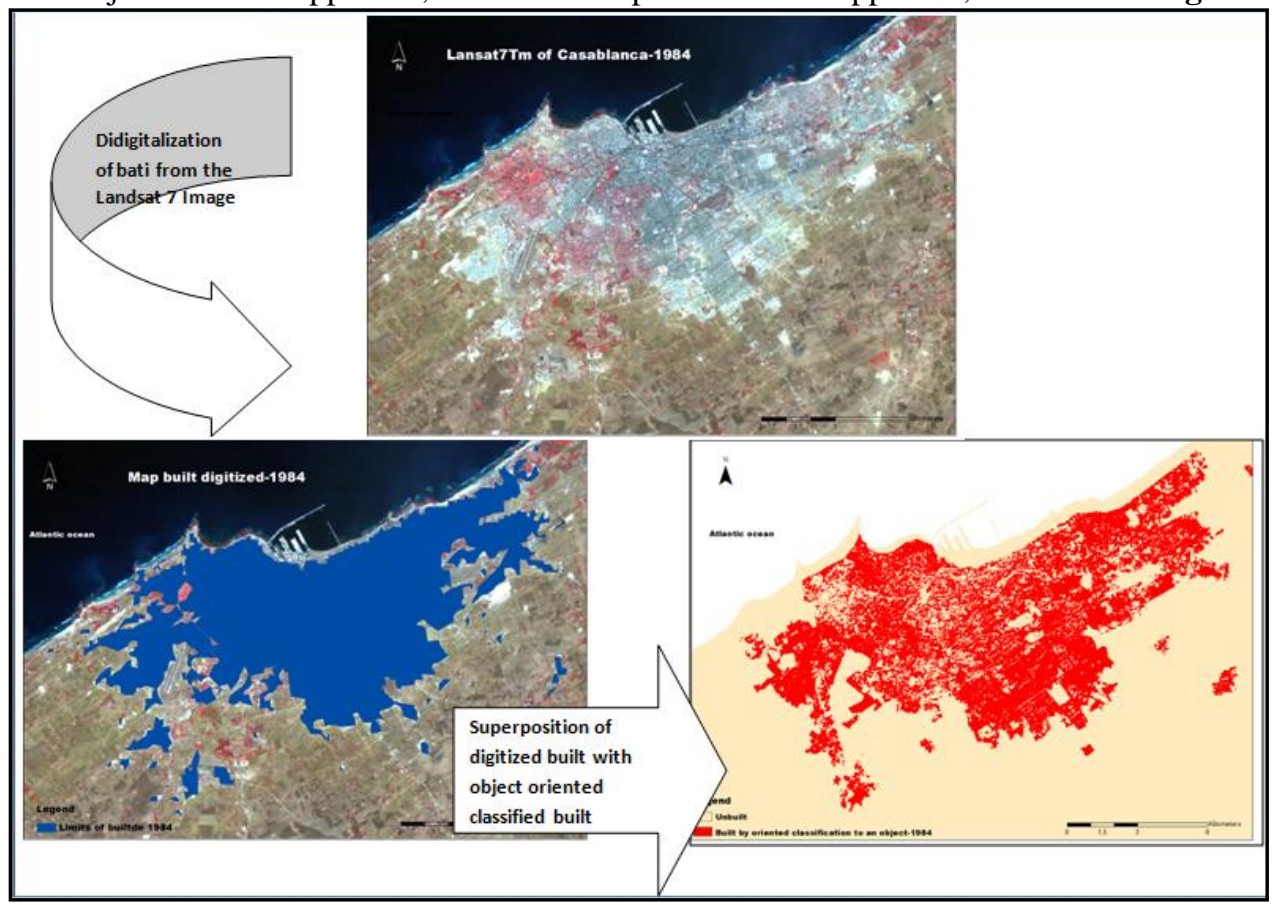

Figure 5:- 1984 Mount map digitized from the satellite image of the same date.

Following this result, the classification of the satellite images for other dates is done using the object-oriented approach. Figure 6 shows the results of the extraction of urban areas obtained for the three dates considered namely in 1984, 1999 and 2015. 


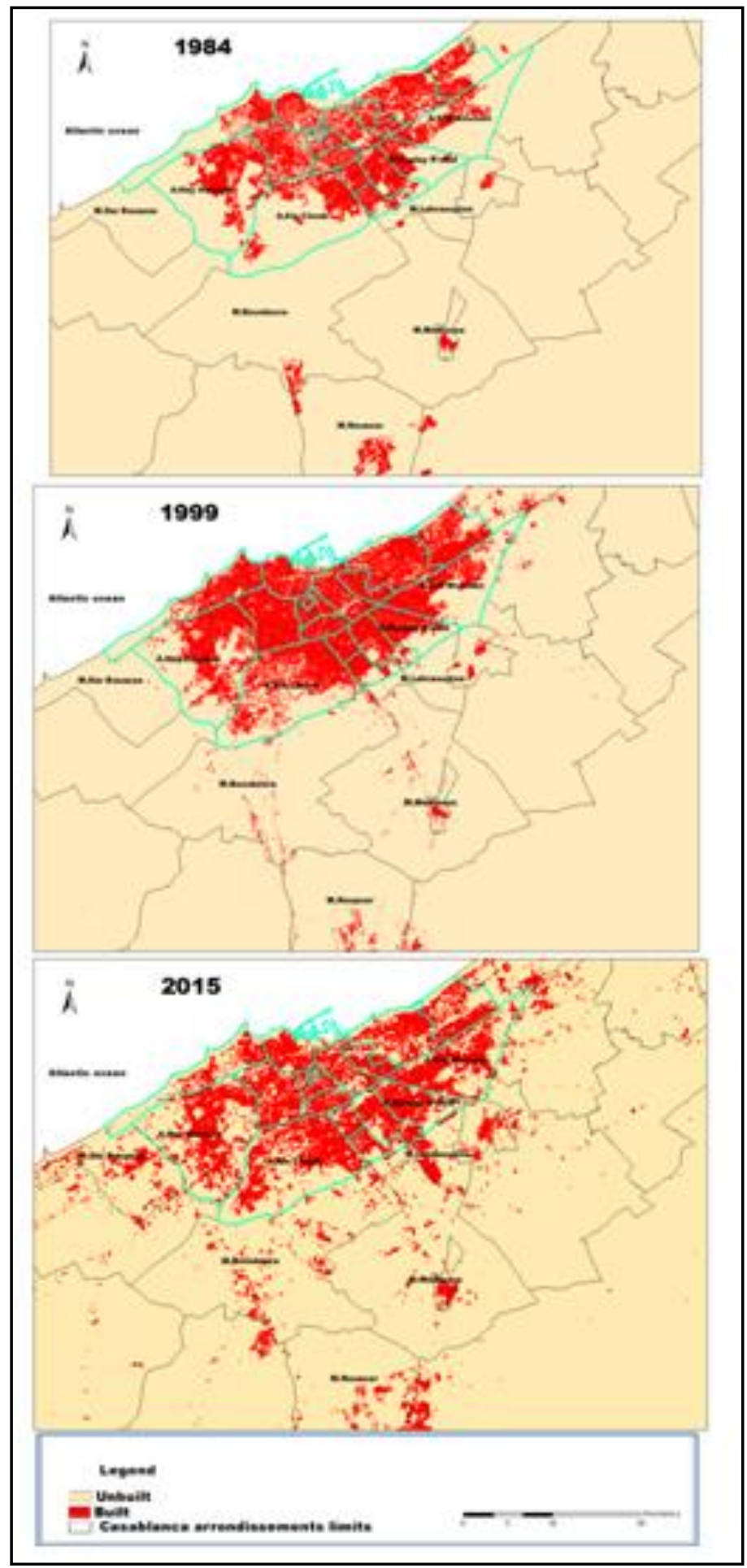

Figure 6:- Maps of urban areas from satellite images for all three dates.

The built evolution between 1984, 1999 and 2015:-

Filtering and cleaning were carried out on the multi-date cards one by one to make the exchange card.

This map illustrated in Figure 7 was performed by combining the maps of urban areas developed using the methodology referred to above. 


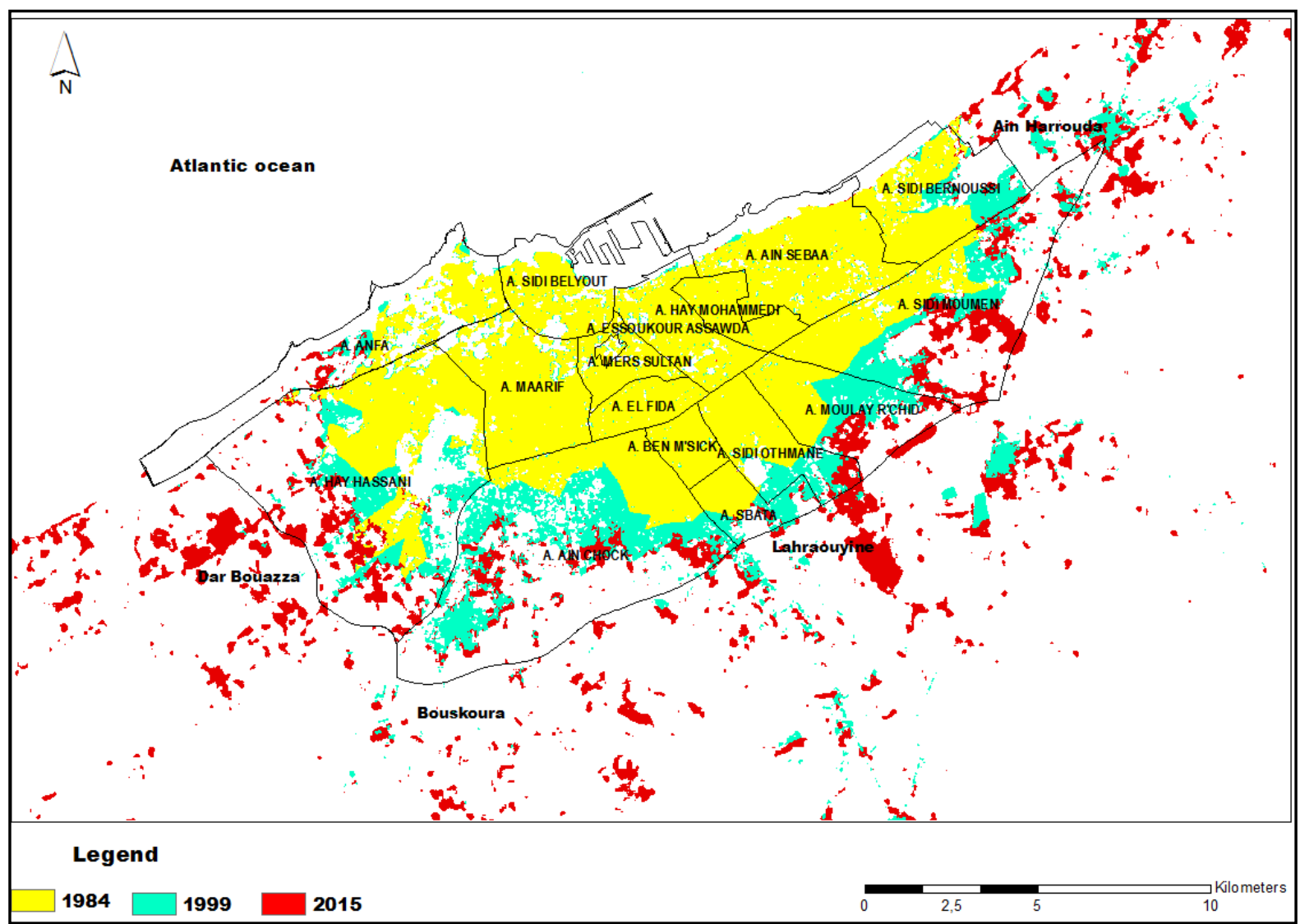

Figure 7:- Map showing the extension of built between 1984-1999-2015.

\section{Discussion and interpretation:-}

\section{General evolution of the urbanized area:-}

From Figure 6, in particular between 1984 and 1999, urban sprawl is felt throughout the ElJadida, Nouacer, Médiouna axes and especially along the coast towards Mohammedia.

Between 1999 and 2015, it is clear that this space-time expansion is radially to the periphery especially the South East (A.Sidi Moumen, A.Moulay R'chid and Lahraouyine) and to the West-SouthWest (A. Hay Hassani, A.Ain Chock, Bouskoura, Errahma) where urbanized areas progressively denser in function of time.

This overtakes the choice of 1985 SDAU: Scheme Urban Development Director including the entire territory of the Wilaya of Greater Casablanca and the town of Mansouria. (AUC, Synthesis, 2008) It confirms the coastal linear extension and promotion of polycentrism within the current perimeter of Casablanca by the implementation of new administrative centers (AUC, Synthesis, 2008).

Also the urban margins have been amended in the meantime due to urban sprawl as illustrated in Figure 7. This shows an overview related to the trend of spatial and temporal extension of built-up surfaces.

Some districts (Figure7) tend to be more compact, others are more spaced between the built or diffused areas (North West) .This is due necessarily to the carried strategy by the SDAU namely dedensification downtown towards the periphery with the opening of 25,000 ha new urbanization 2030. (SDAU, G.Casablanca).

Concerning urban development, the increase of the percentage of built areas is shown in Table 3; it is the calculated overall annual urban growth rate. The speed of the urban expansion during 1984-2015 each period is calculated from the formula below:

$$
\mathrm{UES}=\frac{\mathrm{UAn+i}-\mathrm{UA}}{\mathrm{TAn}+\mathrm{i}}
$$

With: UAi the surface of the frame of the initial year, $A U n+i$ is the surface of the frame of the last year of the period TA and $n+i$ the total vears of the period. 
Table 3:- Urban Development statistics.

\begin{tabular}{|l|l|l|l|l|l|}
\hline & $\begin{array}{l}\text { Initial } \\
\text { surface }\left(\mathrm{km}^{2}\right. \\
)\end{array}$ & $\begin{array}{l}\text { Final surface } \\
\left(\mathrm{km}^{2}\right)\end{array}$ & Zone change (\%) & $\begin{array}{l}\text { Expansion } \\
\text { speed(\%/an })\end{array}$ & $\begin{array}{l}\text { Expansion } \\
\left(\mathrm{km}^{2} / \text { year }\right)\end{array}$ \\
\hline Between1984-1999 & 107 & 154.63 & 44.51 & 2.96 & $\mathbf{3 . 1 5}$ \\
\hline Between1999-2015 & 154.63 & 185.82 & 20.17 & 1.26 & $\mathbf{1 . 9 5}$ \\
\hline
\end{tabular}

According to these statistics, the rate of urban growth is significantly higher between 1984 and 1999 with $3.15\left(\mathrm{~km}^{2}\right.$ / year) compared to the last period. This increase can be explained just by the political and administrative action of the state through the construction of large social housing operations to "eradication" of some large slums among others. (EM, 2015). Certainly, the state wanted to remediate any malfunctions of the urgent colonial Planning mainly after the riots of 1981 creating in 1984 the urban agency and establishing the diagram director of the adjusting and the urbanism (SDAU).

On the other hand, the speed of the urban growth between 1999 and 2015 is in the order of $1.95\left(\mathrm{~km}^{2} /\right.$ year $)$

The overall scheme of this city has changed from monocentric to polycentric. It is well demonstrated in our classifications.

\section{Spatial distribution of urban sprawl:-}

To analyze this urban sprawl throughout a deeper way, an evolution of the territorial dynamics study has been analyzed in each Casablanca district as shown in Figure 8.

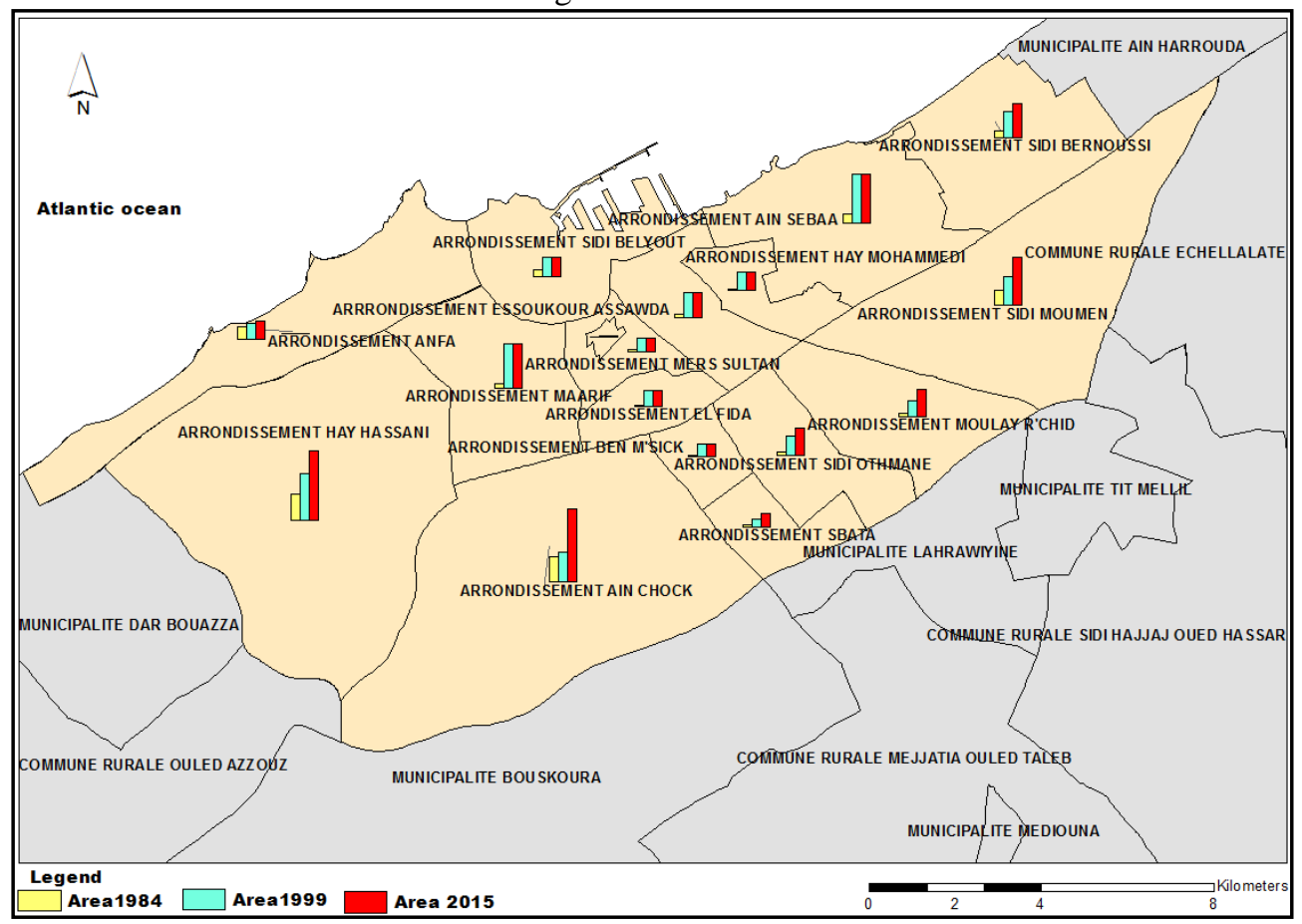

Figure 8:- Map showing the urban dynamic districts between 1984-1999-2015.

From this figure, we see that between 1984 and 1999, the evolution of this dynamic was important in almost all districts except for the case of Anfa district, which indicates a slight change.

But during the most recent period, this dynamic is divided into two categories:

* A Stability concerning districts downtown (Sidi Belyout, Mers Sultan, Maarif).

* A Rebound for the districts located on the outskirts. Urban expansion tends towards the west, southwest, and south-east of the city denser growing districts situated on the outskirts as the case of Hay Hassani, Ain Chok or Sidi Moumen eastward districts. 
To meet the growing needs of the enterprise development and habitat, SDAU created for the territory of CasablancaSettat new land supply with new equipment so as to improve new infrastructure opportunities for business and social life, which facilitated the decongestion of the city -centre and deconcentration of activities and habitat towards the periphery. (AUC Report d. 2008)

Especially after the attacks of 2003, the political will is to create new urban centers to increase social inequalities, ensuring the sustainable socio-economic development and thus maintaining a meshy polycentrism.

Urban Sprawl in terms of the population growth:-

The evolution of urbanized surface area and that of the population are almost parallel (see Figure 9) with slightly different rates depending on the period.

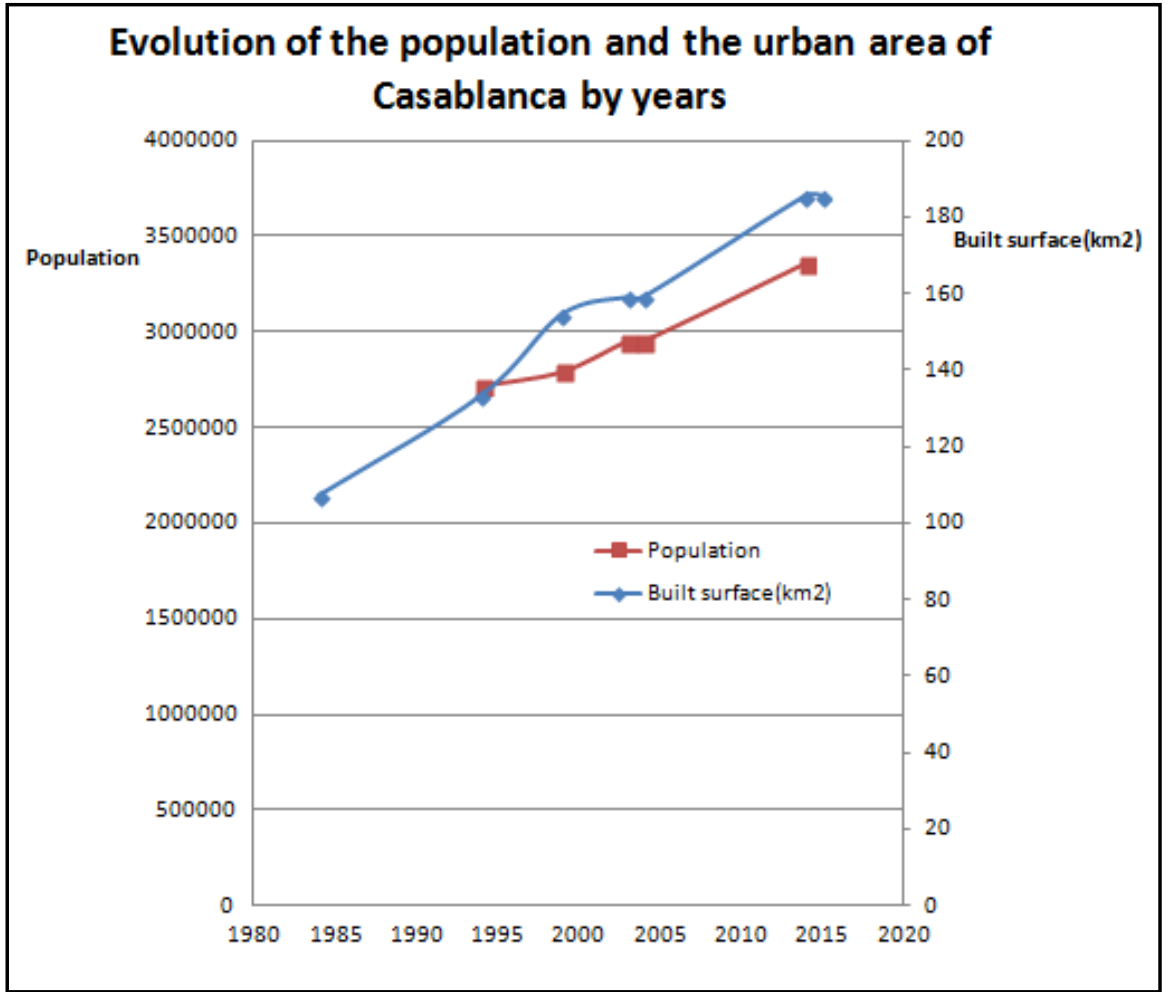

Figure 9:- Population and urban area in Casablanca from 1984 to 2015

The average annual growth rate (AAGR) of the population of the city of Casablanca is only $1.03 \%$ while the AAGR the Casablanca-Settat region under the new division into 12 regions is $1.54 \%$ (RGPH, 2014).

Let us also add that the AAGR of the population of some former central districts dropped (Sidi Belyout (- 1.5\%), El Fida (- 1.6\%), Mers Sultan (- 1.3\%) (AUC, j Report, 2008), but the population AAGR of peripheral urban centers increased (AAGR population is $6.2 \%$ for the provinces of Nouacer and Mediouna.) (RGPH, 2014).

This redistribution of the population is modified and will be modified completely with the urban planning for the creation of new urban centers and the diversion of urban expansion outside the city. The existence of land supply in the periphery and the housing crisis that the city has experienced, all these facts have only accentuated the exodus unlike the urban to the rural areas. This device increases resulted in the development of substandard housing in some neighboring rural areas such as Dar Bouazza, Bouskoura and Lahraouyine. (MRGC, 2010).

Recall that the most economic activity and the Moroccan wealth are concentrated in Casablanca: It is a factor among others for the rapid development of urban areas around the city.

The general trends of the population growth will also be marked up by fertility (birth rate), life expectancy (rate of deaths) and other economic factors that affect the migration. (AUC, j Report, 2008). 


\section{Conclusion:-}

The objective of this study is the analysis of the urban sprawl of Casablanca through the use of techniques of remote sensing. Thus, the selected satellite images were analyzed using a procedure involving pre-treatment methods, the classification and diachronic analysis.

Comparing the two methods of object-oriented classification pixel and concluded that the latter provides more conclusive results as for the extraction of urban areas and raise the most remarkable benefits of this approach with its very close approach of the photo- interpretation.

Although changes in Casablanca built space are revealed through this study during the past three decades, the territorial dynamics of this city remains complex and elusive views different interactions demographic, political, economic and environmental burden in this territory.

However, this study showed the character of the Casablanca urban sprawl that has grown from a mono-centric to a polycentric form. The urbanization has changed the morphology of the city by turning back the agricultural space for the benefit of built space and denser neighborhoods.

These results generally show the direction of the urban growth. Sustainable development should be present in all areas to coordinate between the various economic, social and environmental sides.

\section{References:-}

1. Agence urbaine de Casablanca, Rapport justificatif du Schéma Directeur d'Aménagement Du Grand Casablanca(2008).Pages: 10-20-23-35-37 http://jardindenouaceur.e-monsite.com/medias/files/rpt9-sdau-version-250708.pdf

2. Agence urbaince de Casablanca.Synthèse du Schéma Directeur d'Aménagement Urbain du Grand Casablanca(SDAU) (2008)..Pages: 10-14-16-17. http://www.auc.ma/docs/124112008133350.pdf

3. Equipe Marges(2015). Marges et villes. Programme ANR/Entre exclusion et intégration/Cas méditerranéens.2.Casablanca. http://marges.hypotheses.org/242

4. GLOVIS: USGS Global Visualization Viewer, http://glovis.usgs.gov/

5. H.C.P (Haut -Commissariat au plan).Population de Casablanca au niveau des arrondissements de 19942004-2014.http://www.hcp.ma.

6. LandsatDataContinuityMission.USGS.

7. http://landsat.gsfc.nasa.gov/pdf_archive/20101119_LDCMbrochure.pdf

8. Lassieur Stéphanie (2006). UTILISATION DE LA TELEDETECTION ET DES THECNIQUES SIG POUR DETECTER ET PREVENIR LES ACTIVITES DE DEFORESTATION ILLEGALES, NATO NC3 Agency (La Haye, Pays-Bas), Mars-Septembre.Pages17-19.

9. Lucy Chepkosgei Chepkochei. (2011), OBJECT-ORIENTED IMAGE CLASSIFICATION OF INDIVIDUAL TREES USING ERDAS IMAGINE OBJECTIVE: CASE STUDY OF WANJOHI AREA, LAKE NAIVASHA BASIN, KENYA .Geothermal Development Company. Pages1-3-4.

10. L.Sparfel, F.Gourmelon, Iwan Le Berre. (2008).Approche orientée-objet de l'occupation des sols en zone côtière. Revue télédetection. Page240.

11. MRGC. (2010).Haut-commissariat au Plan. Direction Régionale Du Grand Casablanca. Monographie de la région du Grand Casablanca. Pages14-20.

12. Olivier De Joinville (2016). Traitements appliqués par photo-interprétation, Traitement numérique des images de télédétection, $3^{\text {ème }}$ partie. http://fad.ensg.eu/moodle/course/search.php

13. ONU-HABITAT (2014). L'ETAT DES VILLES AFRICAINES 2014 Réinventer la transition urbaine Programme des Nations Unies pour les Etablissements Humains.

14. RGPH (2014).Note de présentation des premiers résultats du Recensement Général de la Population et de l'Habitat .Pages3-6-8.

15. http://rgph2014.hcp.ma/Note-sur-les-premiers-resultats-du-Recensement-General-de-la-Population-et-de-1Habitat-2014_a369.html

16. Ruiz, Acost,(2013).Francisco Eugenio Gonzalez,.Javier Marcello Ruiz ,Ferran Marqués Acosta .Manuel de télédétection spatiale. TELECAN .Pages56-131-184-246. 
17. http://www.grss-ieee.org/wp-content/uploads/2014/07/FR_TUTORIAL_COMPLETO.pdf

18. Schéma Directeur d'Aménagement Urbain de la région du grand Casablanca. Vision Casablanca 2030.Pages:5-6-11.

http://www.leconomiste.com/sites/default/files/Sch\%C3\%A9ma\%20directeur\%20d'am\%C3\%A9nagement\%20 urbain\%20du\%20Grand\%20Casablanca_0.pdf

19. Taylor et Francis Series in Remote Sensing Applications (2014). Global Urban Monitoring and Assessment through earth observation. Pages310.

20. World Urbanization. Prospects (2014). The 2014 Revision. High lights. Department of Economic and Social Affairs. United Nations. New York. Pages1-17. http://esa.un.org/unpd/wup/highlights/wup2014-highlights.pdf .

21. Yannick Lanthier(2009).Apport de la segmentation d'image hyperspectrale à la précision de la classification en milieu agricole : analyse multi-échelles. Thèse présentée à la faculté des études supérieures et postdoctorales. Ottawa. Pages : 17-21.

22. Yeh,A.G.,and Li,X.(2001).Measurement and Monitoring of Urban Sprawl in a Rapidly Growing Region Using Entropy, Photogrammetric Engineering et Remote Sensing,67.Pages269.

http://www.isprs.org/proceedings/xxxviii/part7/a/pdf/269_XXXVIII-part7A.pdf . 